\title{
Allometric scaling of aerobic fitness outputs in school-aged pubertal girls
}

\author{
André O. Werneck, ${ }^{1,2,3}$, Jorge Conde ${ }^{4}$, Manuel J. Coelho-e-Silva ${ }^{5,6,7^{*}}$, Artur Pereira ${ }^{6}$, Daniela C. Costa ${ }^{5,6,8}$, \\ Diogo Martinho 5,6,9, João P. Duarte ${ }^{5,10}$, João Valente-dos-Santos ${ }^{5,11,12,13}$ (1) Rômulo A. Fernandes ${ }^{3}$, \\ Mariana B. Batista ${ }^{1,14}$, David Ohara ${ }^{2}$, Edilson S. Cyrino ${ }^{2}$ and Enio R. V. Ronque ${ }^{1,2}$
}

\begin{abstract}
Background: This study aimed to determine the allometric exponents for concurrent size descriptors (stature, body mass and fat-free mass) and also to examine the contribution of chronological age and pubertal status combined with above mentioned size descriptors to explain inter-individual variability in the peak of oxygen uptake $\left(\mathrm{VO}_{\text {2peak }}\right)$ among girls during circumpubertal years.

Methods: The final sample included 51 girls (10.7-13.5 years). $\mathrm{VO}_{2 \text { peak }}$ was derived from an incremental progressive maximal protocol using a motorized treadmill. Anthropometry included body mass, stature and skinfolds. Measurements were performed by a single trained observer. Sexual maturation was assessed as self-reported stage of pubic hair (PH) development. Static allometric models were explored as an alternative to physiological output per unit of size descriptors. Allometry also considered chronological age and sexual maturation as dummy variable ( $\mathrm{PH} 2$ vs. $\mathrm{PH} 3$ and $\mathrm{PH} 3$ vs. $\mathrm{PH} 4)$.

Results: Scaling coefficients for stature, body mass and fat-free mass were 1.463 ( $95 \% \mathrm{Cl}: 0.476$ to 2.449), 0.516 (95\%Cl: 0.367 to 0.666$)$ and 0.723 ( $95 \% \mathrm{Cl}: 0.494$ to 0.951$)$, respectively. The inclusion of sexual maturation increased explained variance for $\mathrm{VO}_{2 \text { peak }}$ ( $55 \%$ for $\mathrm{PH} 2$ vs. $\mathrm{PH} 3$ and $47 \%$ for $\mathrm{PH} 3$ vs. PH4). Body mass was identified as the most prominent body size descriptor in the $\mathrm{PH} 2 \mathrm{vs}$. $\mathrm{PH} 3$ while fat-free mass was the most relevant predictor combined with $\mathrm{PH} 3$ vs. PH4.

Conclusions: Body mass and fat-free mass seemed to establish a non-linear relationship with $\mathrm{VO}_{2 \text { peak. }}$. Across puberty, inter-individual variability in $\mathrm{VO}_{2 \text { peak }}$ is explained by sexual maturation combined with whole body during early puberty and by sexual maturation and fat-free mass during late puberty. Additional studies need to confirm ontogenetic allometric models during years of maximal growth.
\end{abstract}

Keywords: Static allometry, Cardiorespiratory fitness, Body composition, Puberty growth spurt, Physical fitness

\section{Background}

Maximal oxygen uptake corresponds to the highest rate of oxygen consumption measured during incremental exercise test and reflects the cardiorespiratory fitness (CRF) of an individual during prolonged exercise. In addition, it is widely recognized as the best single measure of aerobic fitness [1]. All-cause mortality rates were studied in a large sample of men and women who were

\footnotetext{
* Correspondence: mjcesilva@hotmail.com

${ }^{5}$ CIDAF (uid/dtp/04213/2019), University of Coimbra, Coimbra, Portugal

${ }^{6}$ Faculty of Sports Sciences and Physical Education, University of Coimbra,

Coimbra, Portugal

Full list of author information is available at the end of the article
}

exposed to a preventive medical examination including physical fitness measured by a maximal treadmill exercise test [2] and conclusions demonstrated that high levels of physical fitness appeared to delay all-cause mortality primarily due to lowered rates of cardiovascular disease and cancer. Meantime, among children and adolescents, high levels of CRF were also believed to decrease the risk factors for cardiovascular diseases, such as obesity, high blood pressure, dyslipidemia, insulin resistance, among others [3].

Inter-individual variability in absolute peak oxygen uptake $\left(V \mathrm{O}_{2 \text { peak }}\right)$ is associated with functional characteristics and size of the lungs, heart and skeletal muscle [4].

(c) The Author(s). 2019 Open Access This article is distributed under the terms of the Creative Commons Attribution 4.0 International License (http://creativecommons.org/licenses/by/4.0/), which permits unrestricted use, distribution, and reproduction in any medium, provided you give appropriate credit to the original author(s) and the source, provide a link to the Creative Commons license, and indicate if changes were made. The Creative Commons Public Domain Dedication waiver (http://creativecommons.org/publicdomain/zero/1.0/) applies to the data made available in this article, unless otherwise stated. 
Oxygen uptake is often expressed per unit of body size (body mass or fat-free mass) in the literature. Nevertheless, variation in body size is not easily summarized by a single anthropometric variable and although body mass is probably the most popular size descriptor, a recent study [5] considered alternative size descriptors, such as: whole body fat-free mass and lower-limb mass. The preceding observations were based on males spanning late childhood through adolescence who were involved in organized competitive soccer. Meantime, the standard ratio $\left(\mathrm{mL} \cdot \mathrm{kg}^{-1} \cdot \mathrm{min}^{-1}\right)$ has theoretical and mathematical limitations [6]. Scaling exponents are an alternative approach to accommodating inter-individual variability in body size regarding the interpretation of physiological variables as they provide size-free outputs [7].

Growth refers to the increase in the size of the body as a whole and of its parts. During the second decade of life, young people are expected to become taller and heavier showing an increase in lean and fat tissues, also, their organs increase in size. Heart volume and mass, for example, follow a growth pattern like that for body mass [8], while the lungs and their functions grow proportionally to stature. Adolescence is characterized by the growth spurt and sexual maturation. Maturation refers to progress towards the biologically mature state and should be viewed as a source of substantial inter-individual variability in almost all size descriptor. In the context of Physical Education, teachers should be careful in using cut-points. Many fitness batteries are associated with sex and age-specific tables to interpret performance values. This especially affects youngsters contrasting in biological maturation who need differential amount of time to keep working at improving.

Static allometric models can be useful to accommodate both size descriptors and maturity status or chronological age (CA) variable in the same model aiming to predict $V \mathrm{O}_{\text {2peak }}$ [9]. Therefore, this study aimed to estimate the allometric exponents for different size descriptors (stature, body mass and fat-free mass) as well as the contribution of CA and pubertal status combined with size descriptors to explain inter-individual variability in $V \mathrm{O}_{2 \text { peak }}$ among girls during circumpubertal years.

\section{Methods}

\section{Procedures}

The current project was approved by the Research Ethics Committee for studies involving human participants of the State University of Londrina and University Medical Center of Northern Parana (CEP/UEL/202-07) and subsequently presented by the research leader to school boards and teachers. After obtaining institutional approval, a signed informed consent containing the objectives, protocols, and risks was obtained from parents or legal guardians and each participant. During the first visit, adolescents were informed that their participation was voluntary and that they could discontinue at any time. Procedures were conducted in accordance with the Declaration of Helsinki for human studies of the World Medical Association. Participants were recruited from schools in Londrina, State of Paraná, Brazil. After completing the data collection in the school, participants visited the laboratory of the State University of Londrina. The two data collections were performed within a 1-week period. $V \mathrm{O}_{2 \text { peak }}$ was derived from a laboratory test using a motorized treadmill and a brief anthropometric battery was considered as part of the measurements during the final testing session. Indoor temperature in the laboratory was controlled to remain within the above-mentioned range $\left(20-24{ }^{\circ} \mathrm{C}\right)$.

\section{Participants}

The sample included 54 girls (10-13 years). Chronological age was calculated to the nearest 0.1 year from birth date minus testing date. The unique inclusion criteria were related to physical constraints that temporarily or permanently prevented the individual to participate in motor activities. Additionally, three adolescents were not included after checking for outliers.

\section{Sexual maturation}

Pubic hair $(\mathrm{PH})$ development was assessed using a self-assessment protocol based on drawings of the stages (1-5) as described by Tanner [10]. Participants were asked to compare themselves to the drawings and inform their perception regarding the similarity of their own $\mathrm{PH}$ development and stages summarized in the drawings. Due to the low prevalence of PH5, 4 adolescents were excluded from the main analysis.

\section{Anthropometry}

Measurements were obtained by a single experienced observer using standardized procedures. Body mass and stature were measured to the nearest $0.1 \mathrm{~kg}$ and $0.1 \mathrm{~cm}$ using a scale (SECA 770, Hanover, MD, USA) and a stadiometer (Harpenden 98.603, Holtain Ltd., Croswell, UK), respectively. Skinfold thickness was assessed at the triceps and subscapular right side. Three measurements were obtained and the median value was retained for analysis. Technical errors of measurement were $1.02 \mathrm{~mm}$ and $0.72 \mathrm{~mm}$ for the triceps and subscapular, respectively, using a Lange caliper (Cambridge Scientific Instruments, Cambridge, MD) using standard technics [11]. Percentage of fat mass was estimated from skinfolds as independent variables [12] and fat mass and fat-free mass were subsequently calculated in $\mathrm{kg}$. 


\section{Peak oxygen uptake}

Direct assessment of $V \mathrm{O}_{2 \text { peak }}$ was conducted in a laboratory through open circuit spirometry with the performance of a progressive and maximum test on a treadmill ergometer. The test began with warm-up exercises for 3 min at a rate of $6 \mathrm{~km} \cdot \mathrm{h}^{-1}$ and $0 \%$ slope, after which the slope was increased to $1 \%$ and the speed increased by 1 $\mathrm{km} \cdot \mathrm{h}^{-1}$ every minute, maintaining the same slope, up to completion of the test. The protocol adopted was tested in a previous pilot study in which adolescents with the same characteristics and age reached maximum effort in a time interval between 8 and $12 \mathrm{~min}$, which has been recommended to obtain aerobic power indicators in young people [13]. To measure $V \mathrm{O}_{2}$ during the test, a portable gas analyzer model K4 b2 (Cosmed, Rome, Italy) was used. The oxygen and carbon dioxide analyzers were calibrated before each test according to the manufacturer's instructions. Respiratory parameters were recorded breath-bybreath, which in turn were averaged over a 15-s period. The criteria adopted for the completion of the test have been previously detailed [14] and were as follows: (a) subject's voluntary exhaustion, with the request to finish the test; (b) reaching the maximum heart rate predicted for age (220 - age); (c) respiratory exchange ratio exceeding 1.1; (d) detection of a plateau in the $\mathrm{VO}_{2}$ curve, defined by an increase of less than $2 \mathrm{~mL} \cdot \mathrm{kg}^{-1} \cdot \mathrm{min}^{-1}$ in the $\mathrm{VO}_{2}$ with change of stage in the test.

\section{Data analysis}

Descriptive statistics (mean, standard deviation) were calculated for the total sample and the KolmogorovSmirnov test was used to assess normality. Appropriate logarithmic transformations were adopted to obtain normal distributions. Simple linear regression was adopted to estimate allometric coefficients of body size descriptors with $V \mathrm{O}_{2 \text { peak }}$ as dependent variable. Equation 1 was used. Values of $a$ and $k$ were derived from linear regressions of the logarithmic regression transformations as illustrated by Eq. 2 .

$$
\begin{aligned}
& y=a^{k} \times \varepsilon \\
& \ln (y)=\ln (a)+k \times \ln (x)+\ln (\varepsilon)
\end{aligned}
$$

Multiple linear regression was performed to examine the association between body size descriptors and chronological, as well as between body size descriptors and sexual maturation (dummy coded variables of $\mathrm{PH}$ : $\mathrm{PH} 2$ vs. $\mathrm{PH} 3$ and PH3 vs. PH4) - see Eqs. 3 and 4, respectively.

$$
\begin{aligned}
\ln \left(\mathrm{VO}_{2 \text { peak }}\right)= & k_{1} \times \ln (\text { body descriptor })+a \\
& +\mathrm{b} \times(\mathrm{CA})
\end{aligned}
$$

$$
\begin{aligned}
\ln \left(\mathrm{VO}_{2 \text { peak }}\right)= & k_{1} \times \ln (\text { body descriptor })+a \\
& +\mathrm{b} \\
& \times \mathrm{PH} \text { stage }(\text { dummy coded } \mathrm{PH})
\end{aligned}
$$

All analysis were done using IBM SPSS 22.0 (SPSS, Inc., Chicago, IL). Significance level was set at $5 \%$ for all inferential statistics.

\section{Results}

From the initial sample $(n=54)$, three girls were excluded due to missing data, thus the final sample was composed of 51 girls, from which, $21.6 \%$ were obese. Characteristics of the sample are described in Table 1. Aged ranged between 10.7 and 13.5 years. Dependent $\left(V \mathrm{O}_{2 \text { peak }}\right)$ and independent (stature, body mass and fat-free mass) variables assumed a normal distribution.

Table 2 presents simple allometric models of $V \mathrm{O}_{2 \text { peak }}$ using different size descriptors. The coefficients did not cross the linearity [body mass: 0.516 (95\% CI: 0.367 to 0.666); fat-free mass: 0.723 (95\%CI: 0.494 to 0.951 )], with exception of stature [1.463 (95\%CI: 0.476 to 2.449$)$ ]. The most explicative size descriptor was body mass $\left(R^{2}=0.486\right)$.

The association between crude size descriptors and $V \mathrm{O}_{2 \text { peak }}$ is presented in Fig. 1 . The most explicative size descriptor was body mass, with a $\mathrm{r}^{2}$ of 0.499 . Moreover, scaled $V \mathrm{O}_{2 \text { peak }}$ according to $\mathrm{PH}$ categories is presented on Fig. 2. PH groups presented no differences for all scaled $V \mathrm{O}_{2 \text { peak }}$ (for stature, body mass and fat-free mass).

Multiplicative allometric models of $\mathrm{VO}_{2 \text { peak }}$ combining different body size descriptors and $\mathrm{CA}$ are described in Table 3. In general, CA remained significant only in the model of fat-free mass and the explanation of the models did not changed substantially from simple allometric models, ranging between 16 and $48 \%$.

Table 4 presents the best multiplicative allometric models of $V \mathrm{O}_{2 \text { peak }}$ combining body size descriptors and dummy stages of $\mathrm{PH}$ transitions (PH2 to $\mathrm{PH} 3$ and $\mathrm{PH} 3$ to PH4). The models included in the table were the models that best predicted $V \mathrm{O}_{2 \text { peak }}$ in each transition of $\mathrm{PH}$. Model of body mass was what best described VO2peak in the transition between $\mathrm{PH} 2$ and $\mathrm{PH} 3$, explaining 55\% of $V \mathrm{O}_{\text {2peak }}$ 's variation. Moreover, fat-free mass was the model that better described $\mathrm{VO}_{2 \text { peak }}$ in the transition between $\mathrm{PH} 3$ and $\mathrm{PH} 4$, explaining $47 \%$ of the variation.

\section{Discussion}

Aerobic fitness is an important component of physical fitness and is recognized as a protective factor for several negative outcomes as chronic diseases $[15,16]$ and mortality in adulthood [17]. It is often marked through $V \mathrm{O}_{2 \text { peak }}$ that is consensually considered the best single indicator. During the adolescent years, CRF is associated with metabolic risk, independent of potential 
Table 1 Descriptive statistics for the total sample $(n=51)$ and test for normality

\begin{tabular}{|c|c|c|c|c|c|c|c|c|c|}
\hline \multirow[t]{2}{*}{ Variable } & \multirow[t]{2}{*}{ Unit } & \multirow[t]{2}{*}{$f$} & \multirow[t]{2}{*}{ Range } & \multicolumn{3}{|l|}{ Mean } & \multirow{2}{*}{$\begin{array}{l}\text { Standard } \\
\text { deviation }\end{array}$} & \multicolumn{2}{|c|}{ Komolgorov-Smirnov } \\
\hline & & & & $\overline{\text { Value }}$ & SEM & $(95 \% \mathrm{Cl})$ & & Value & $p$ \\
\hline \multicolumn{10}{|c|}{ Pubic hair development } \\
\hline Stage 2 & & 16 & & & & & & & \\
\hline Stage 3 & & 20 & & & & & & & \\
\hline Stage 4 & & 11 & & & & & & & \\
\hline Stage 5 & & 4 & & & & & & & \\
\hline \multicolumn{10}{|l|}{ Body mass index } \\
\hline Normal weight & & 40 & & & & & & & \\
\hline Overweight/obese & & 11 & & & & & & & \\
\hline Chronological age & years & & $10.7-13.5$ & 12.0 & 0.09 & (11.8 to 12.2 ) & 0.6 & 0.084 & 0.20 \\
\hline Stature & $\mathrm{cm}$ & & $147.9-151.7$ & 149.8 & 0.96 & (147.9 to 151.7 ) & 6.8 & 0.067 & 0.20 \\
\hline Body mass & $\mathrm{kg}$ & & $27.6-75.3$ & 43.5 & 1.51 & (40.5 to 46.5$)$ & 10.8 & 0.118 & 0.07 \\
\hline Fat-free mass & $\mathrm{kg}$ & & $23.3-47.1$ & 32.8 & 0.75 & (31.3 to 34.3 ) & 5.3 & 0.071 & 0.20 \\
\hline $\mathrm{VO}_{2 \text { peak }}$ & $L \cdot \min ^{-1}$ & & $1.06-2.55$ & 1.80 & 0.04 & (1.71 to 1.88$)$ & 0.30 & 0.112 & 0.20 \\
\hline
\end{tabular}

SEM standard error of the mean, $95 \% \mathrm{Cl} 95 \%$ confidence interval, $\mathrm{VO}_{2}$ oxygen uptake

confounders $[18,19]$. Variation in descriptors of body size and composition may be a consequence intervention for weight loss or training sessions aimed to increase muscle mass, but also of growth and biological maturation, especially during puberty growth spurt. By inference, caution is needed in the interpretation of absolute parameters of maximal oxygen uptake and also of traditional ratio. In this sense, power functions with allometric scaling exponents are proposed $[9,20,21]$. The current study used allometric scaling to evaluate the interrelationship among indicators of body size, composition, and parameters of aerobic fitness.

Growth refers to changes in body size and it has implications in proportionality, shape, and composition since different organs and tissues present distinct growth curves including the biological determinants of aerobic fitness such as heart and pulmonary sizes and functions [22-25]. Relationships among length, surface area and volume have implications for metabolism and thermoregulation [26]. Linear anthropometric descriptors such as stature are unidimensional. Areas including body surface area or muscle cross-sectional areas are bi-dimensional constructs $(\mathrm{d}=2)$ and, finally, body volume is considered a tri-dimensional descriptor $(\mathrm{d}=3)$. Meantime, considering time (minutes) as an uni-dimensional variable, absolute values of oxygen uptake measured in L. $\mathrm{min}^{-1}$ corresponds to (d3-d1) and when oxygen uptake is divided by body mass in order to dissociate $V \mathrm{O}_{2 \text { peak }}$ from body size $(\mathrm{d} 3)$, isometric bodies stature corresponds to mass raised to $2 / 3$ power function (assumption of geometric similarity). The current study obtained significant single allometric models that explained substantial percentages of inter-individual variability in $V \mathrm{O}_{2 \text { peak }}$ (between 14 and $49 \%$ ). As presented in Table 2, body mass was the best single predictor using allometric modeling. However, the scaling coefficient for body mass was 0.516 (95\% CI: 0.367 to 0.666 ) which is below the exponent of 0.67 that provided support for geometric similarity $[1,26]$. The mean values for body mass and stature in the current sample plotted at, or slightly above, age-specific 50th percentile of US reference data [27]. Surprisingly, the scaling coefficient for stature was near to linearity 1.463 ( $95 \%$ CI: 0.476 to 2.449 ) which was below the expected value suggested by the assumptions of geometric similarity $\left[\mathrm{VO}_{2}(\mathrm{~L} \cdot \mathrm{min}-1)\right.$ divided by stature $(\mathrm{cm})$ corresponds to 3-1 divided by 1 ]. Consequently, pubertal status was hypothesized as source of inter-individual variation among school girls. In multiplicative allometric equations (Table 3), the addition of CA to the models of

Table 2 Allometric modeling of $\mathrm{VO}_{2 \text { peak }}$ using different body size descriptors $(\mathrm{n}=51)$

\begin{tabular}{|c|c|c|c|c|c|}
\hline \multicolumn{4}{|c|}{$\ln \left(V_{2 \text { peak }}\right)=\ln (a)+k \times \ln (X i:$ size descriptor $)+\ln (\varepsilon)$} & \multicolumn{2}{|c|}{ Model summary } \\
\hline \multirow{2}{*}{$\begin{array}{l}\text { Xi } \\
\text { (size descriptor) }\end{array}$} & \multirow[t]{2}{*}{ Constant } & \multicolumn{2}{|c|}{ k-exponent } & \multirow[t]{2}{*}{$\overline{R^{2}}$} & \multirow{2}{*}{$\begin{array}{l}\text { Adjusted } \\
R^{2}\end{array}$} \\
\hline & & Value & $(95 \% \mathrm{Cl})$ & & \\
\hline Stature & -6.753 & 1.463 & (0.476 to 2.449$)$ & 0.154 & 0.136 \\
\hline Body mass & -1.360 & 0.516 & (0.367 to 0.666$)$ & 0.486 & 0.486 \\
\hline Fat-free mass & -1.939 & 0.723 & (0.494 to 0.951$)$ & 0.452 & 0.441 \\
\hline
\end{tabular}

$\mathrm{VO}_{2}$ oxygen uptake, $95 \% \mathrm{Cl} 95 \%$ confidence interval 


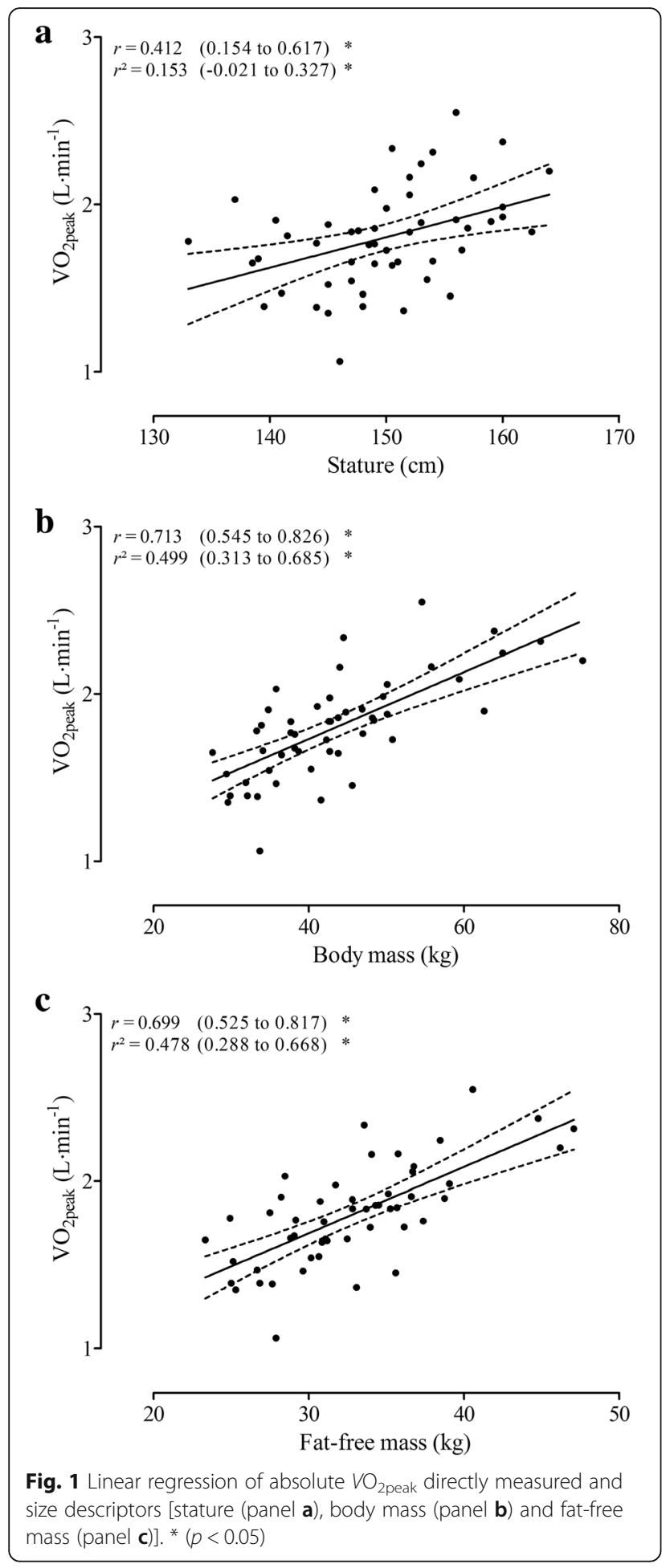

size descriptors did not substantially change the prediction of $V \mathrm{O}_{2 \text { peak }}$. Moreover, proportional static models with the inclusion of stage of $\mathrm{PH}$ development as dummy variables (PH2 vs. $\mathrm{PH} 3$ and $\mathrm{PH} 3$ vs. PH4) increased the explained variance (55\% for $\mathrm{PH} 2$ vs. $\mathrm{PH} 3$ and $47 \%$ for $\mathrm{PH} 3$ vs. $\mathrm{PH} 4$ ) and body mass was kept as the most prominent body size

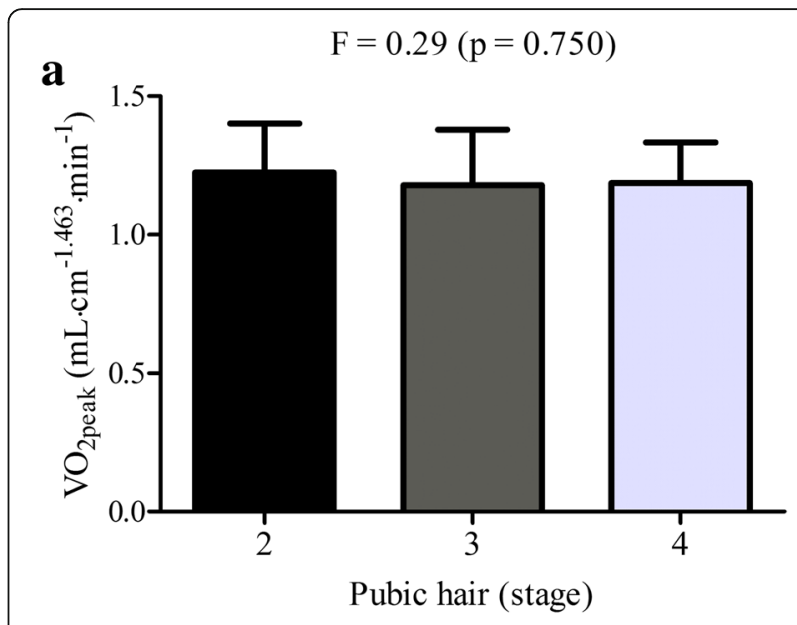

b $\quad \mathrm{F}=0.39(\mathrm{p}=0.679)$

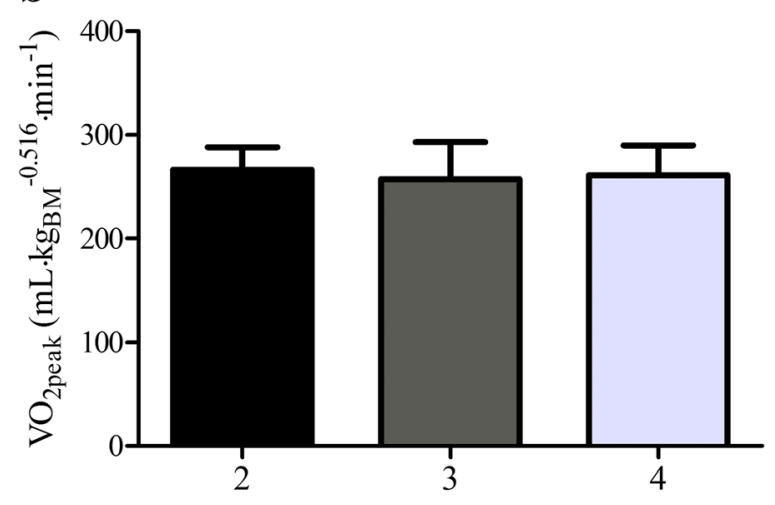

Pubic hair (stage)

c $\quad \mathrm{F}=0.81(\mathrm{p}=0.453)$

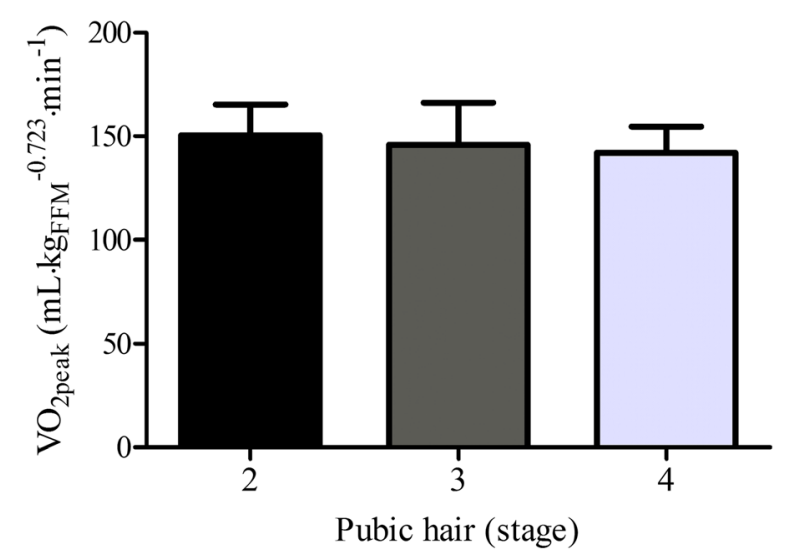

Fig. 2 Mean values ( \pm SD) of directly measured $V O_{2 \text { peak }}$ expressed by stature (panel a), body mass (panel $\mathbf{b}$ ) and fat-free mass (panel $\mathbf{c}$ ), considering the derived scaling coefficients, by stage of pubic hair $(\mathrm{PH})$ 
Table 3 Multiplicative allometric modeling of the absolute $\mathrm{VO}_{2 \text { peak }}$ combining body size descriptors with chronological age $(\mathrm{n}=51)$

\begin{tabular}{|c|c|c|c|c|c|c|c|}
\hline \multicolumn{5}{|c|}{$\ln \left(\mathrm{VO}_{2 \text { peak }}\right)=\mathrm{k} \times \ln (\mathrm{Xi}$ : size descriptor $)+a+\mathrm{b} \times(\mathrm{Z}$ : chronological age $)+\ln (\varepsilon)$} & \multicolumn{3}{|c|}{ Model Summary } \\
\hline $\begin{array}{ll}a \\
\end{array}$ & $\mathrm{Xi}_{\mathrm{i}}$ & Z & Exponent & $(95 \% \mathrm{Cl})$ & $\bar{R}$ & $R^{2}$ & Adjusted $R$ \\
\hline \multirow[t]{2}{*}{-7.144} & Stature & & 1.676 & (0.668 to 2.685$)$ & 0.443 & 0.196 & 0.163 \\
\hline & & Chronological age & -0.058 & $(-0.131$ to 0.015$)$ & & & \\
\hline \multirow[t]{2}{*}{-1.010} & Body mass & & 0.518 & (0.369 to 0.667$)$ & 0.713 & 0.508 & 0.487 \\
\hline & & Chronological age & -0.023 & $(-0.078$ to 0.033$)$ & & & \\
\hline \multirow[t]{2}{*}{-1.378} & Fat-free mass & & 0.768 & (0.544 to 0.992$)$ & 0.708 & 0.502 & 0.481 \\
\hline & & Chronological age & -0.061 & $(-0.117$ to -0.005$)$ & & & \\
\hline
\end{tabular}

$\mathrm{VO}_{2}$ oxygen uptake, $95 \% \mathrm{Cl} 95 \%$ confidence interval

descriptor in the $\mathrm{PH} 2$ vs. $\mathrm{PH} 3$ while fat-free mass was the most relevant predictor combined with $\mathrm{PH} 3$ vs. $\mathrm{PH} 4$.

The previous information confirms that simple ratio for reporting $V \mathrm{O}_{2 \text { peak }}$ by size descriptors have limitations during puberty growth spurt [6]. The beginning of sexual maturation corresponds to increments in stature and body mass including non-isometric variation on intrinsic components affecting oxygen uptake such as heart size and pulmonary function [22-24]. Stages of puberty provide an indication of biological maturation. Secondary sex characteristics (breast and PH in girls, genital and PH in boys) are widely used, and at times misused, in studies of young athletes. Overt manifestation of breast, genital development and appearance of the first hair marks the transition into stage 2. During puberty growth spurt, peak height velocity occurs in stages 3,4 and 5 of $\mathrm{PH}$ development. However, PH development represents the onset of adrenarche (increased secretion of hormones by the adrenal cortex) and not necessarily the onset of true pubertal development [10]. The percentage of females in each stage of $\mathrm{PH}$ development at attainment of peak height velocity and attainment of menarche were studied in 75 girls aged 8-15 years from Saskatchewan Pediatric Bone Mineral Accrual Study [28]. Menarche occurred later in PH development with the majority of the girls in PH4 (59.6\%) and PH5 (31.9\%) while peak height velocity was distributed in stage PH3 (42.5\%) and PH4 (47.5\%).

In the current study, fat-free mass emerged as the most relevant size descriptor with the progression of sexual maturation. Fat-free mass is the most metabolically active tissue $[23,29]$ and peak velocities of body mass and fat-free mass occurs in different moments and usually after peak height velocity that tend to occur at stage 3 and 4 [8]. Meantime, adolescence corresponds to a period of reduction in physical activity among girls with the increasing $\mathrm{CA}$ and biological maturation is viewed as mediating effect in lifestyle and intentions to exercise [30] which may also negatively contribute to aerobic fitness level.

A few limitations need to be recognized in the present study. The sample size was not large enough and did not equally cover the stages of sexual maturation. Body fat and fat-free mass were estimated from anthropometry (skinfold thickness) and currently, other methods are available (bioimpedance, air displacement plethysmography). Additionally, assessment of biological maturation was given by stages of sexual maturation which comprises several limitations [8]. Within the literature there is a substantial variability of average ages reported for adolescent attaining a stage of development for a secondary sex characteristic. For example, 11.56 years were reported for girls entering PH3 among 1494 girls from the cross-sectional Pécs Growth Study [31] which is substantially early compared to an average age of 12.84 years reported in third National Health and Nutrition Examination Survey [32]. Moreover, this last cited study also concluded that Non-Hispanic black girls had an earlier sexual development for $\mathrm{PH}$ and breast development either by median age at entry for a stage or for the mean age for a stage than Mexican American or non-Hispanic white girls. Studies devoted to ethnic variation of $\mathrm{PH}$ development in Brazil were not available.

Table 4 Multiplicative allometric modeling of the absolute $\mathrm{VO}_{2 \text { peak }}$ combining size descriptors and sexual maturation

\begin{tabular}{|c|c|c|c|c|c|c|c|}
\hline \multicolumn{5}{|c|}{$\ln \left(\mathrm{VO}_{2 \text { peak }}\right)=\mathrm{k} \times \ln ($ size descriptor $)+a+\mathrm{b} \times \mathrm{PH}$ stage $($ dummy coded $)+\ln (\varepsilon)$} & \multicolumn{3}{|c|}{ Model Summary } \\
\hline \multirow[t]{2}{*}{$a$} & \multicolumn{4}{|c|}{ Parameters } & & & \\
\hline & Size descriptor & PH stage & Exponent & $(95 \% \mathrm{Cl})$ & $R$ & $R^{2}$ & Adjusted $R^{2}$ \\
\hline \multirow[t]{2}{*}{-1.505} & Body mass & & 0.565 & (0.392 to 0.737$)$ & 0.757 & 0.574 & 0.548 \\
\hline & & $\mathrm{PH} 2$ vs $\mathrm{PH} 3$ & -0.042 & $(-0.124$ to 0.040$)$ & & & \\
\hline \multirow[t]{2}{*}{-2.814} & Fat-free mass & & 0.978 & (0.582 to 1.373$)$ & 0.710 & 0.504 & 0.468 \\
\hline & & $\mathrm{PH} 3$ vs $\mathrm{PH} 4$ & -0.054 & $(-0.165$ to 0.057$)$ & & & \\
\hline
\end{tabular}

$\mathrm{VO}_{2}$ oxygen uptake, $\mathrm{PH}$ pubic hair development, $95 \% \mathrm{Cl} 95 \%$ confidence interval Note: Only significant models were included 
Skeletal age is recognized as the best indicator of biological maturation, although its application is costly and requires a small dose of radiation exposure and trained technicians [33]. Moreover, the prevalence of obesity in our sample was considerable $20 \%$, what can influence the scaling coefficients and consequently, the results of the present study only can be inferred for non-athlete samples that present similar obesity rates. Finally, the cross-sectional design does not permit causality between size, maturation and maximal oxygen uptake.

The direct estimation of $V \mathrm{O}_{2 \text { peak }}$ in school population and allometric approach should be recognized as the strength aspects of the present study and the data fits previous literature claiming for the analysis in young people [34]. The findings obtained in the current study have practical implications. Among untrained healthy school girls, stature seemed to present an almost linear relationship with maximal oxygen uptake. The three-dimensional size descriptors (body mass and fat-free mass) established a non-linear relationship with $V \mathrm{O}_{2 \text { peak }}$ and across puberty inter-individual variability is explained by multiple combination of sexual maturation with body mass during mid-puberty and sexual maturation and fat-free mass during the transition for late-puberty to post-puberty.

\section{Conclusions}

In conclusion, the traditional ratio by body mass should be used with caution to monitor the effects of Physical Education and other training or educational program regarding progresses of aerobic fitness throughout elementary school girls, given that the ratio by one unity of body mass can underestimate CRF of adolescent girls, especially with overweight and obese. Moreover, during the beginning of puberty (PH2-PH3), body mass was the best predictor of CRF, while fat-free mass was the best predictor of CRF during late puberty (PH3-PH4) and thus should be used in the ratio of $V \mathrm{O}_{2 \text { peak }}$ with the appropriate allometric scaling coefficient for a better description of CRF.

\section{Abbreviations}

CA: Chronological age; CRF: Cardiorespiratory fitness; PH: Pubic hair; $\mathrm{VO}_{2 \text { peak: }}$ : Peak oxygen uptake

\section{Acknowledgments}

Authors would like to express thanks to all the participants for their engagement in this study.

\section{Funding}

CIDAF is supported by the Portuguese Foundation for Science and Technology (uid/dtp/04213/2019). DCC (SFRF/BD/136193/2018), DM (SFRH/ BD/121441/2016), JPD (SFRH/BD/101083/2014) and JVdS (SFRH/BPD/100470/ 2014) were partially supported by the Portuguese Foundation for Science and Technology. ESC was partially supported by a grant of the National Council of Technological and Scientific Development (CNPq/Brazil). ERVR was partially supported by a grant of the Foundation for the Support of Scientific and Technological Development of Paraná (FAADCT/Brazil). No other current funding sources for this study. The funders played no role in the design, collection, analysis or interpretation of the data, nor in the preparation of the manuscript or decision to submit the manuscript for publication.

\section{Availability of data and materials}

The dataset supporting the conclusions of the current study is available from the corresponding author on reasonable request.

\section{Authors' contributions}

Conceived and designed the experiments: AOW MJCS RAF MBB ESC ERVR. Performed the experiments: AOW RAF MBB DO ESC ERVR. Analyzed the data: JC MJCS DCC DM JPD JVdS. Data interpretation: AOW JC MJCS AP DCC DM JPD JVdS RAF MBB DO ESC ERVR. Wrote the paper: AOW JC MJCS AP DCC DM JPD JVdS MBB DO. Revised manuscript content: AOW JC MJCS AP DCC DM JPD JVdS RAF MBB DO ESC ERVR. Approved final version of manuscript AOW JC MJCS AP DCC DM JPD JVdS RAF MBB DO ESC ERVR. All authors read and approved the final manuscript.

Ethics approval and consent to participate

The current project was approved by the Research Ethics Committee for studies involving human participants of the State University of Londrina and University Medical Center of Northern Parana (CEP/UEL/202-07) and subsequently presented by the research leader to school boards and teachers. After obtaining institutional approval, signed informed consent containing the objectives, protocols, and risks was obtained from parents or legal guardians and each participant. During the first visit the adolescents were informed that their participation was voluntary and that they could discontinue at any time. Procedures were conducted in accordance with the Declaration of Helsinki for human studies of the World Medical Association.

\section{Consent for publication}

Not applicable.

\section{Competing interests}

João Valente-dos-Santos is an editorial board member of BMC Pediatrics. The rest of the authors declare that they have no competing interest.

\section{Publisher's Note}

Springer Nature remains neutral with regard to jurisdictional claims in published maps and institutional affiliations.

\section{Author details}

${ }^{1}$ Study and Research Group in Physical Activity and Exercise (GEPAFE), State University of Londrina (UEL), Londrina, Paraná, Brazil. ${ }^{2}$ Study and Research Group in Metabolism, Nutrition, and Exercise (GEPEMENE), State University of Londrina (UEL), Londrina, Paraná, Brazil. ${ }^{3}$ Scientific Research Group Related to Physical Activity (GICRAF), Laboratory of InVestigation in Exercise (LIVE), Department of Physical Education, São Paulo State University, Presidente Prudente, São Paulo, Brazil. ${ }^{4}$ School of Health and Technology, Polytechnic Institute of Coimbra, Coimbra, Portugal. ${ }^{5}$ CIDAF (uid/dtp/04213/2019), University of Coimbra, Coimbra, Portugal. ${ }^{6}$ Faculty of Sports Sciences and Physical Education, University of Coimbra, Coimbra, Portugal. ${ }^{7}$ Universidade de Coimbra, Estadio Universitario, Pavilhao III, 3040-156 Coimbra, Portugal. ${ }^{8}$ Portuguese Foundation for Science and Technology (SFRF/BD/136193/2018), Lisbon, Portugal. ${ }^{9}$ Portuguese Foundation for Science and Technology (SFRH/BD/121441/2016), Lisbon, Portugal. ${ }^{10}$ Portuguese Foundation for Science and Technology (SFRH/BD/101083/2014), Lisbon, Portugal.

${ }^{11}$ Portuguese Foundation for Science and Technology (SFRH/BPD/100470/ 2014), Lisbon, Portugal. ${ }^{12}$ Institute for Biomedical Imaging and Life Sciences (IBILI), Faculty of Medicine, University of Coimbra, Coimbra, Portugal.

${ }^{13}$ Faculty of Physical Education and Sport, Lusófona University of Humanities and Technologies, Lisbon, Portugal. ${ }^{14}$ Federal University of Mato Grosso do Sul (UFMS), Pantanal Campus, Corumbá, Brazil.

Received: 20 October 2018 Accepted: 19 March 2019

Published online: 08 April 2019

\section{References}

1. Armstrong N, Welsman JR. Aerobic fitness. In: Armstrong N, van Mechelen W, editors. Paediatric exercise science and medicine. Oxford: Oxford University Press; 2008. p. 97-108.

2. Blair SN, Kohl HW, Paffenbarger RS, Clark DG, Cooper KH, Gibbons LW, Physical fitness and all-cause mortality. A prospective study of healthy men and women. JAMA. 1989;262(17):2395-401. 
3. Anderssen SA, Cooper AR, Riddoch C, Sardinha LB, Harro M, Brage S, et al. Low cardiorespiratory fitness is a strong predictor for clustering of cardiovascular disease risk factors in children independent of country, age and sex. Eur J Cardiovasc Prev Rehabil. 2007;14(4):526-31.

4. Rowland T. Children's exercise physiology. Champaign, IL: Human Kinetics; 2005

5. Valente-Dos-Santos J, Coelho-E-Silva MJ, Tavares OM, Brito J, Seabra A Rebelo A, et al. Allometric modelling of peak oxygen uptake in male soccer players of 8-18 years of age. Ann Hum Biol. 2015;42(2):125-33.

6. Tanner JM. Fallacy of per-weight and per-surface area standards, and their relation to spurious correlation. J Appl Physiol. 1949;2(1):1-15.

7. Nevill AM, Markovic G, Vucetic V, Holder R. Can greater muscularity in larger individuals resolve the $3 / 4$ power-law controversy when modelling maximum oxygen uptake? Ann Hum Biol. 2004;31(4):436-45.

8. Malina RM, Bouchard C, Bar-Or O. Growth, Maturation, and Physical Activity. Champaign: Human Kinetics; 2004.

9. Nevill AM, Holder RL. Modelling maximum oxygen uptake: a case-study in non-linear regression model formulation and comparison. J R Stat Soc Ser. 1994:43(4):653-66.

10. Tanner JM. Growth at adolescence. Oxford: Blackwell Scientific; 1962.

11. Harrison G, Buskirk E, Carter L, Johnston F, Lohman T, Pollock M. Skinfold thicknesses and measurement technique. In: Lohman TG, Roche AF, Martorell R, editors. Anthropometric standardization reference manual. Champaign: Human Kinetics; 1988. p. 55-70.

12. Slaughter MH, Lohman TG, Boileau RA, Horswill CA, Stillman RJ, Van Loan $M D$, et al. Skinfold equations for estimation of body fatness in children and youth. Hum Biol. 1988;60(5):709-23.

13. Rowland TW. Pediatric laboratory exercise testing: clinical guidelines. Champaign, IL: Human Kinetics; 1993.

14. Batista MB, Cyrino ES, Arruda M, Dourado AC, Coelho-E-Silva MJ, Ohara D, et al. Validity of equations for estimating VO2peak from the 20-m shuttle run test in adolescents aged 11-13 years. J strength Cond Res. 2013;27(10): 2774-81.

15. Spencer RM, Heidecker B, Ganz P. Behavioral cardiovascular risk factors effect of physical activity and cardiorespiratory fitness on cardiovascular outcomes. Circ J. 2016;80(1):34-43.

16. Lakoski SG, Willis BL, Barlow CE, Leonard D, Gao A, Radford NB, et al. Midlife cardiorespiratory fitness, incident cancer, and survival after cancer in men: the cooper center longitudinal study. JAMA Oncol. 2015;1(2):231-7.

17. Nauman J, Nes BM, Lavie CJ, Jackson AS, Sui X, Coombes JS, et al. Prediction of cardiovascular mortality by estimated cardiorespiratory fitness independent of traditional risk factors: the HUNT study. Mayo Clin Proc. 2017:92(2):218-27.

18. Silva $D$, Werneck AO, Collings $P$, Tomeleri CM, Fernandes RA, Ronque $E$, et al. Cardiorespiratory fitness is related to metabolic risk independent of physical activity in boys but not girls from southern Brazil. Am J Hum Biol. 2016;28(4):534-8.

19. Machado-Rodrigues AM, Leite N, Coelho-e-Silva MJ, Martins RA, Valente-dosSantos J, Mascarenhas LPG, et al. Independent association of clustered metabolic risk factors with cardiorespiratory fitness in youth aged 11-17 years. Ann Hum Biol. 2014;41(3):271-6.

20. Nevill AM, Ramsbottom R, Williams C. Scaling physiological measurements for individuals of different body size. Eur J Appl Physiol Occup Physiol. 1992; 65(2):110-7.

21. Loftin M, Sothern M, Abe T, Bonis M. Expression of VO2peak in children and youth, with special reference to allometric scaling. Sport Med. 2016;46(10): 1451-60.

22. Malcolm DD, Burns TL, Mahoney LT, Lauer RM. Factors affecting left ventricular mass in childhood: the Muscatine study. Pediatrics. 1993;92(5):703-9.

23. Reynolds EL. Sexual maturation and the growth of fat, muscle and bone in girls. Child Dev. 1946;17(3):121-44.

24. Wang XB, Dockery DW, Wypij D, Gold DR, Speizer FE, Ware JH, et al. Pulmonary-function growth velocity in children 6 to 18 years of age. Am Rev Respir Dis. 1993;148(6 Pt 1):1502-8.

25. Katch VL, Katch FI. Use of weight-adjusted oxygen uptake scores that avoid spurious correlations. Res Q. 1974;45(4):447-51.

26. Mcmahon T. Size and shape in biology. Science. 1973;179(4079):1201-4.

27. Center for Disease Control and Prevention. National Center for Health Statistics. United States: CDC growth charts; 2000.

28. Sherar LB, Baxter-Jones ADG, Mirwald RL. Limitations to the use of secondary sex characteristics for gender comparisons. Ann Hum Biol. 2004 31(5):586-93.
29. Sheng HP, Huggins RA. A review of body composition studies with emphasis on total body water and fat. Am J Clin Nutr. 1979;32(3):630-47.

30. Cumming SP, Sherar LB, Pindus DM, Coelho-e-Silva MJ, Malina RM, Jardine PR. A biocultural model of maturity-associated variance in adolescent physical activity. Sch Heal. 2012;5(1):37-41.

31. Dóber I, Királyfalvi L. Pubertal development in south-Hungarian boys and girls. Ann Hum Biol. 1993;20(1):71-4.

32. Sun SS, Schubert CM, Chumlea WC, Roche AF, Kulin HE, Lee PA, et al. National estimates of the timing of sexual maturation and racial differences among US children. Pediatrics. 2002;110(5):911-9.

33. Beunen GP, Rogol AD, Malina RM. Indicators of biological maturation and secular changes in biological maturation. Food Nutr Bull. 2006;27(4SGS):244-56.

34. Nevill AM, Bate S, Holder RL. Modeling physiological and anthropometric variables known to vary with body size and other confounding variables. Am J Phys Anthropol. 2005;128(41):141-53.
Ready to submit your research? Choose BMC and benefit from:

- fast, convenient online submission

- thorough peer review by experienced researchers in your field

- rapid publication on acceptance

- support for research data, including large and complex data types

- gold Open Access which fosters wider collaboration and increased citations

- maximum visibility for your research: over $100 \mathrm{M}$ website views per year

At BMC, research is always in progress.

Learn more biomedcentral.com/submissions 